\title{
Exploring the influence of transformational leadership on work engagement and workplace spir- ituality of academic employees in the private higher education institutions in Malaysia
}

\author{
Anantha Raj A. Arokiasamy ${ }^{a^{*}}$ and Huam Hon Tat ${ }^{b}$
}

${ }^{a}$ Xiamen University Malaysia, School of Economics and Management, Jalan Sunsuria, Bandar Sunsuria, 43900 Sepang, Selangor, Malaysia ${ }^{b}$ Putra Business School, 43400 UPM Serdang, Selangor, Malaysia

\section{CHRON I C L E}

\section{Article history:}

Received: September 172019

Received in revised format: September 292019

Accepted: October 10, 2019

Available online:

October 10, 2019

Keywords:

Higher education

Transformational leadership

Work engagement

Workplace spirituality

Academic employees

\section{A B S T R A C T}

This paper reports the findings of a study examining the relationship between transformational leadership, work engagement and workplace spirituality of academic employees in four PHEIs in Malaysia. The perceptions of academic employees regarding the transformational leadership style, work engagement and workplace spirituality were assessed in an empirical study on a sample of 369 full-time academic employees working in higher education institutions in Malaysia. The study found a satisfactorily good level of influence between transformational leadership and workplace spirituality and work engagement. The paper also provides insights into enhancing employees work engagement via transformational leaders through their abilities to create workplace spirituality. The findings also provide evidence that transformational leaders play a crucial role in shaping workplace spirituality and employee's level of work engagement in an emerging country work setting.

(C) 2020 by the authors; licensee Growing Science, Canada

\section{Introduction}

The significance of effective leadership and management for the successful operation of schools and colleges has been increasingly acknowledged in the $21^{\text {st }}$ century. This study advances a small but growing body of knowledge on leadership processes to highlight the complexity of leadership within a distinct group of people outside the Western sample. Malaysia was selected for this study because the country has been rapidly transformed over recent decades and continue to grow economically, creating a fertile workplace leadership environment. Culturally, Malaysia's mix of ethnic and religious groups, as well as its British colonial heritage, creates and environment that appears to be continually evolving in terms of traditional patterns of leadership and business management (Ansari et al., 2004). This study also draws on an emerging body of knowledge that has investigated leadership models within Asian context in general and the Malaysian setting in particular (Rahman et al., 2015). It is well accepted that leadership models (specifically transformational and transactional) have primarily been derived from the Western perspectives, as Western-led research has tended to use non-Asian organizations as the basis for empirical investigation. However, there is a growing evidence that there is much to learn from Asian-based contexts because of the culturally diverse perspectives in the region (Ansari et al., 2004). To understand the Asian approach to business management, it is often the leaders who drive the change processes and ensure the long-term survival of organizations. Understanding the unique Asian perspectives on leadership and how Asian leaders manage their workforce in growth economies, may help advance notions of leadership. Furthermore, effective leadership in diverse societies requires unique capabilities that have not been extensively reported in the Western literature (Rahman et al., 2016).

This article contends that transformational leadership serves as an antecedent to employee workplace spirituality. Transformational leader motivates by increasing self-efficacy in followers, by facilitating social identification within a group and by linking organizational values to follower values. This allows followers to feel more determined in their work and augments

* Corresponding author

E-mail address: anantharaj.arokiasamy@xmu.edu.my (A. R. A. Arokiasamy) 
their perceived empowerment. Transformational leadership brings about the same feeling of empowerment in all followers; it is the unique aspect of transformational leadership that enables and inspires followers toward change in organizations and in the process, achieve performance beyond expectation (Nielsen et al., 2008). Based on the above reasons, this study will empirically test the influence of transformational leadership on workplace spirituality and also examine the mediating effect of work engagement in the relationship between them. The conceptual model guiding this research is depicted in Fig. 1.

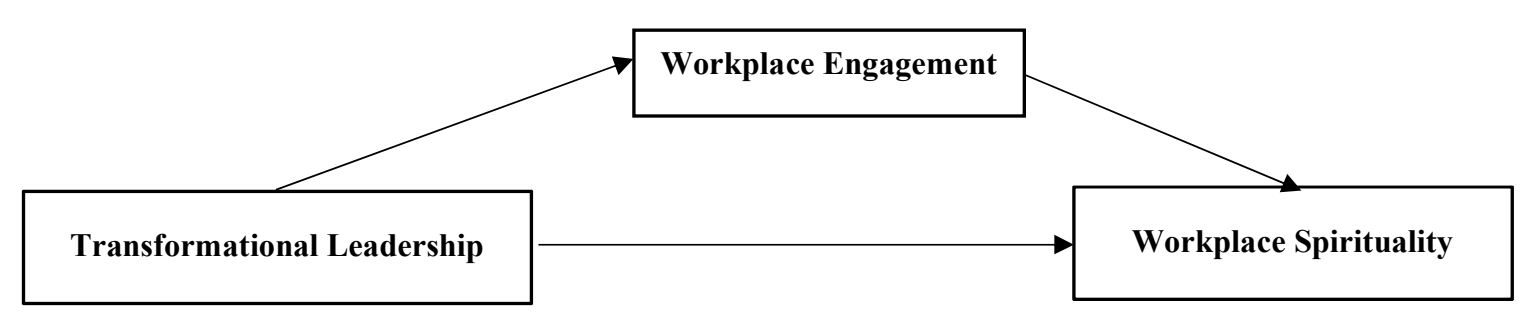

Fig. 1. The Conceptual Model

Talent retention is one of the biggest challenges for organizations today. Employee resignations are not new; neither are the reasons - dissatisfaction or unhappiness with their job or boss, new opportunities and changing career. Retaining key talent must rise to the top of every organization's strategic agenda. As costly as it is to replace a departing employee, even more costly is the competitive advantage lost with each employee who walks out the door. This recognition clearly speaks volume on why this level of research is needed in the higher educational environment. People have a need to know that their efforts, energy and time will contribute to the success of the organization. Identifying a significant association between these variables augur well for more expanded studies in the higher educational setting to retain, re-train and increase job morale and satisfaction while reducing work stress of academic employees in the PHEIs in Malaysia.

\section{Review of Literature and Hypotheses}

The ongoing economic growth in Malaysia has necessitated organizations to change their size, function and operation to suit the demands of a new service economy. However, the research on managing and leading a diverse group of employees in Malaysia has not kept pace with its market growth and environmental change. Most of what we know about Malaysian leadership, business philosophies and management of the workforce is derived from studies conducted in the 1990s and in the early $21^{\text {st }}$ century. Recent exceptions include the work of Selvarajah and Meyer (2008) who examined the gap between implicit leadership theory and actual leaders' behaviour among Malaysian managers and Sandhu et al. (2011) who investigated the influence of distinct ethnic groups on leadership in Malaysia. Chong et al. (2004) also investigated expertise and experience on organizational performance in Malaysia and Sohail and Daud (2009) explored organizational commitment and leadership styles in Malaysia. Similarly, Rahman et al. (2015) used transformational and transactional leadership models within the Malaysian workplace context as the basis of their investigation but instead, concentrated on job satisfaction and organizational commitment.

More recently, Fachrunnisa and Adhiatma (2014) in comparing management orientation of employees in Malaysia and the USA, also offered insight into leadership perceptions of Malaysian employees. Their results showed that Malaysian respondents were more focused on their relationships than the tasks. This emerging body of work offers insight into the Malaysian cultural context and has added to our knowledge of diverse leadership practices. Other studies using the Malaysian setting which have emerged more recently have considered a range of topics including international joint ventures (Geh \& Tan, 2009), leadership in manufacturing (Nguyen \& Mohamed, 2011) and the effect of procedural justice in promotion decisions in multinational companies in Malaysia (Rani et al., 2008). These studies, although not specifically examining leadership and culture, do offer a developing understanding of the Malaysian workforce in the contemporary era. Indeed, given the recent transformation in Malaysia's economic and political spheres, we need to know more about Malaysian leadership in the workplace setting. It is important to acknowledge the rapid changes in the external environment and incorporate them in the study of leading and influencing employees and teams in organizations. A comprehensive understanding of how leaders lead people in such complex societies is an important form of knowledge that may expand management theories.

In addition, studies have shown that leaders in Malaysia are viewed as "special" because they set directions and make decisions. Wahid and Mustamil (2014) found evidence that leadership authority is neither questioned nor challenged because it is viewed as an organized hierarchy to maintain workplace harmony. In a sense, it is easy to sustain the authority attached to the role of leadership in the Malaysian context because communal living practices strongly endorse the need for tolerance, compromise and consensus between superiors and subordinates. This form of acceptance of power and status is further strengthened by the custom of respect for elders and seniority. In the Malaysian societal system, the acceptance of authority is highly valued and used as a means of building sustainable working relationships. Subordinates, therefore, believe in the natural goodness of the leader and accept that the leader's direction will benefit others (Abdullah \& Kaliannan, 2006). Therefore, the 
high Western individualism dimension, which promotes the leadership practices of "challenge the process" or "laying things on the table for open and direct confrontation" to influence followers, is not necessarily an appropriate model for explaining leadership practice in Malaysia. By overly relying on theories from the Western perspective, where, individualism, group dynamics, role expectations and power positions differ significantly from the Asian context, the generalizability of leadership theories can, therefore, be questioned. This limitation is likely to form "reservations" about the relevance of the concept of leadership styles beyond the Western environment. This study aims to address this gap.

\subsection{Transformational Leadership Style}

Transactional and transformational leaderships have become the main focus of leadership theories in recent years. Transactional leaders emphasize work standards and have task-oriented aims in mind; they perform leadership within organizational constraints by clarifying the responsibilities of subordinates (Bass \& Avolio, 1993). In contrast, transformational leaders are people with inspirational values. They exhibit nurturing, caring behaviours and display consideration towards subordinates. Transformational leadership focus on the ability to identify potential in followers and leaders learn how to encourage and motivate subordinates to their fullest capabilities (Avolio et al., 1993). These leaders inspire followers to reach beyond their ability and capacity to achieve organizational goals. As such, transformational leadership demonstrate four unique behaviours known as intellectual stimulation, idealized influence, inspirational motivation and individualized consideration (Avolio et al., 1993).

Idealized influence incorporates attributes that induce followers to identify with the leader's high moral values and ethical consideration. The leaders exhibit behaviours that emphasize integrity and honesty and demonstrate the importance of those values for individual long-term career success (Avolio et al., 1993). Inspirational motivation has characteristics that draw subordinates' attention to leaders because leaders somehow enthuse and inspire them at work with their actions. In displaying inspirational motivation, leaders focus on articulating organizational direction to subordinates and the importance of aligning one's personal goals with organizational goals. Through inspirational motivation, leaders encourage followers to look at the big picture and plan their career paths accordingly (Avolio et al., 1993). Intellectual stimulation is regarded as a behaviour that stimulates change in subordinates. Change is necessary for creative problem-solving and for undertaking challenging assignments. In addition, by encouraging subordinates to challenge basic assumptions, leaders create an environment where continuous learning takes place (Avolio et al., 1993). In the fourth dimension of transformational leadership, individualized consideration behaviours are highlighted. Here, leaders demonstrate mentoring ability and coaching skills to further develop the followers' individualized needs. Leaders show compassion and are sensitive towards the feelings of their followers by treating them with respect. Followers are valued for their self-worth and contribution and are not treated simply as a group of workers with a set of skills needed to complete day-to-day organizational tasks (Avolio et al., 1993).

\subsection{Workplace Spirituality}

Spirituality is defined as the "basic feeling of being connected with one's complete self, others and the entire universe" (Chawla, 2014). It involves a sense of wholeness, connectedness at work and deep values (Daniel, 2015). Ashmos and Duchon (2000) developed an instrument based on the spirituality literature and tested their conceptualization with a survey of 696 respondents. Their findings revealed three distinct and interesting factors reflecting spirituality; conditions for community, meaning at work and inner life. Furthermore, in a recent review of the spirituality literature, Milliman et al. (2003) argue that workplace spirituality can indeed be manifested in these three dimensions and that the Ashmos and Duchon (2000) instrument thus remains one of the stronger ways to assess spirituality. Given the lack of other, better conceptualizations, therefore, we focus our study on these three manifestations of workplace spirituality.

The first factor; conditions for community, is an indication of the extent to which employees feel that there are conditions present to allow them to be part of a community. In such a community, people can experience personal growth, be valued as individuals and satisfy the important need to belong. Community at work is based on the belief that people see themselves as connected to each other and that there is some sort of connection between one's inner self and other people's inner selves (Dhiman \& Marques, 2010). Furthermore, in such a community, employees can bring their whole self to work within an environment where meaningful interpersonal relationships can blossom. The second factor, known as meaning at work, goes beyond the physical and intellectual experience of work to connote what is important, joyful, energizing and spiritual about work. This spiritual view of work goes also beyond the human relations view of work as being merely interesting, intellectual and satisfying (Ashmos \& Duchon, 2000). The spiritual meaning at work is about "searching for deeper meaning and purpose, living one's dream, feeling good about one's work, expressing one's inner life by seeking meaningful work and contributing to others" (Ashmos \& Duchon, 2000). This factor thus refers to "achieving personal fulfilment or spiritual growth in the workplace" (Rahman et al, 2016). Finally, inner life refers to "an individual's hopefulness, awareness of personal values and concern for connectedness with the universe" (Ashmos \& Duchon, 2000). The inner life dimension of workplace spirituality is based on the assumption that people have both an inner and outer life. By nourishing the inner life through ways such as expressing aspects of one's being at work, one can lead a more meaningful and productive outer life. As such, the recognition of an inner life at the workplace means accepting that people have both a mind and a spirit and the development of the spirit at work is as important as the development of the mind (Ashmos \& Duchon, 2000). 


\subsection{Work Engagement}

Work engagement is a positive, fulfilling, affective motivational state of work-related well-being that can be seen as the antipode of job burnout. Engaged employees have high levels of energy and are enthusiastically involved in their work (Schaufeli et al., 2008). Most scholars agree that engagement includes an energy dimension and an identification dimension. Thus, engagement is characterized by a high level of vigour and strong identification with one's work. Unfortunately, the broad exploration of constructs over the past decade has not produced consensus about its meaning. In contrast, we advocate the use of work engagement as a specific, well-defined and properly operationalized psychological state that is open to empirical research and practical application. We define work engagement as a motivational concept. When engaged, employees feel compelled to strive towards a challenging goal. They want to succeed. Employees accept a personal commitment to attaining these goals. Further, work engagement reflects the personal energy employees bring to their work (Bakker et al., 2008).

Engaged employees not only have the capacity to be energetic, they enthusiastically apply that energy to their work. They do not hold back. They do not keep their energy in reserve for something important; they accept that today's work deserves their energy (vigour). In addition, work engagement reflects intense involvement in work (dedication). Engaged employees pay attention, they consider the important details while getting to the essence of challenging problems. Engaged employees become absorbed in their work, experiencing flow in which they lose track of time and diminish their response to distractions (Bakker et al., 2008). Work engagement pertains to any type of challenging work. It describes employees' ability to bring their full capacity to solving problems, connecting with people and developing innovative services (absorption) (Bakker et al., 2008). Employees' response to organizational policies, practices and structures affect their potential to experience engagement. In a stable work environment, employees maintain a consistent level of work engagement and strive in settings that demonstrate strong connections between corporate and individual values. While engaged employees find their work more enjoyable and turn that enjoyment into more effective action. Hence, we suggest these further propositions.

\section{Hypotheses of the Study}

$\mathrm{H}_{\mathrm{A} 1}$ : The idealized influence, inspirational motivation, intellectual stimulation and individualized consideration associated with transformational leadership style make organizational members more likely to develop workplace spirituality.

$\mathrm{H}_{\mathrm{A} 2}$ : The idealized influence, inspirational motivation, intellectual stimulation and individualized consideration associated with transformational leadership style make organizational members more likely to develop work engagement.

$\mathrm{H}_{\mathrm{A} 3}$ : The vigour, dedication and absorption associated with work engagement make organizational members more likely to develop workplace spirituality.

\section{Methodology}

\subsection{Sample}

The data was collected through self-reported and administered online questionnaire. The sample for the study was mostly drawn from academic employees from PHEIs in Malaysia. All respondents read and checked an informed consent form before taking the surveys. Participation was voluntary and anonymous. A 5-point Likert scale was used for the study in which, 1= "strongly disagree", 2= "disagree", 3= "neutral", 4= "agree", 5= "strongly agree". Out of the 1100 questionnaires emailed, around 480 respondents replied and 369 of them were valid. As suggested by Hair et al. (2010) the filled questionnaires should be checked for missing responses and outliers. A total of 111 questionnaires has to be disregarded as more than 25 percent of the questionnaires were not fully completed by the respondents. Therefore, the effective response rate is 33.5 percent. Average age was 38 years with a standard deviation of 9.92. The research sample included 141 males (38\%) and 228 females (62\%). Sixty-two percent of the sample was female. Average organizational tenure was 11.37 years $(\mathrm{SD}=9.83)$.

\section{Measures}

\subsection{Transformational Leadership}

The six-factor model formed the basics of the MLQ-Form 5X. Avolio et al. (1999) recently revised this form to improve the psychometric properties of the subscales while retaining the six-factor model. The revisions resulted in a 36-item scale. In the review of the literature, MLQ 5X-Short was found to be of a highly reliable scale. The reliability of MLQ 5X-Short in different studies were demonstrated even when it was translated into other languages. For instance, a recent applied study on a sample of 202 employees in a manpower service agency in the Southern United States, found that reliabilities were; (0.98) for transformational style, $(0.89)$ for transactional, and (0.71) for laissez-faire.

\subsection{Work Engagement}

The Utrecht Work Engagement Scale (UWES) was used to measure work engagement. The 17-item scale is composed of three subscales namely vigour (six items) with Cronbach alphas ranging from 0.75 to 0.82 (Schaufeli \& Bakker, 2004), dedication (five items) with Cronbach alphas ranging from 0.88 to 0.90 (Schaufeli \& Bakker, 2004) and absorption (six items) with Cronbach alphas ranging from 0.70 to 0.75 (Schaufeli \& Bakker, 2004); examples of the items include: 
- "At my work, I feel bursting with energy" (vigour)

- "I am enthusiastic about my job" (dedication)

- "When I am working, I forget everything else around me" (absorption).

The internal consistency reported for vigour was 0.85 , for dedication 0.91 and for absorption 0.85 . All the items of the survey, except for the UWES scale, were measured on a 7-point intensity response scale anchored at extreme poles (e.g. "Highly unlikely" 1 - low intensity to "Highly likely" 7 - high intensity).

\subsection{Workplace Spirituality}

In this study, the workplace spirituality scale designed by Ashmos and Duchon (2000) was used as a tool to measure the workplace spirituality of the academic employees. Workplace spirituality scale consist of 23 items. Each item has seven elective responses, which are recorded on 7-point Likert scale fluctuating from strongly disagree to strongly agree. The score allocated to "strongly disagree" be 1 , "moderately disagree" be 2 , "disagree" be 3 , "neutral" 4 , agree 5 , "moderately agree" 6 and "strongly agree" 7. Meaningful work scale contains 8 items and alpha reliability estimate is 0.88 . Sense of community scale contains 7 items and its alpha reliability estimate is 0.91 . Alignment with organizational values scale contains 8 -items and alpha reliability coefficient is 0.94 .

\section{Data Analysis}

This study consists of two analytical steps. Step 1 compiles the demographic data of the 369 respondents which includes gender, age, marital status, years of service, qualification and department. Step 2 consists of Pearson product moment correlations were tested among the extracted factors to determine which of them have a high correlation with the dependent variable; workplace spirituality. Finally, a multiple regression analysis was run to examine which of the extracted factors have the strongest impact on academic employee's workplace spirituality in the PHEIs in Malaysia. These analyses were computed using the software SPSS version 22.0.

\section{Results}

Table 1 presents the descriptive statistics for the study variables. The reliability coefficients for all the scales and subscales exceeded the conventional 0.70 level of acceptance (Hair et al., 2010). The scales and subscales' reliabilities and intercorrelations between the overall scales on the different scales are reported in Table 1. It is clear that all the scales have acceptable reliabilities.

Table 1

Measure of Central Tendency and Scales' Reliability Coefficient

\begin{tabular}{|c|c|c|c|c|c|c|}
\hline Variables & $\mathrm{N}$ & Min & Max & Mean & Std. Dev. (SD) & Alphas $(\alpha)$ \\
\hline \multicolumn{7}{|l|}{ Workplace Spirituality } \\
\hline Conditions for community & 369 & 1.0 & 7.0 & 3.63 & 0.67 & 0.72 \\
\hline Meaning at work & 369 & 1.0 & 7.0 & 3.72 & 0.78 & 0.76 \\
\hline Inner life & 369 & 1.0 & 7.0 & 3.80 & 0.80 & 0.71 \\
\hline \multicolumn{7}{|l|}{ Transformational Leadership } \\
\hline Idealized influence & 369 & 1.0 & 5.0 & 3.38 & 0.88 & 0.89 \\
\hline Inspirational motivation & 369 & 1.0 & 5.0 & 3.14 & 0.62 & 0.91 \\
\hline Intellectual stimulation & 369 & 1.0 & 5.0 & 3.43 & 0.68 & 0.92 \\
\hline $\begin{array}{l}\text { Individualized consideration } \\
\text { Work Engagement }\end{array}$ & 369 & 1.0 & 5.0 & 3.47 & 0.79 & 0.87 \\
\hline Vigour & 369 & 1.0 & 7.0 & 3.28 & 0.73 & 0.81 \\
\hline Dedication & 369 & 1.0 & 7.0 & 2.79 & 1.12 & 0.85 \\
\hline Absorption & 369 & 1.0 & 7.0 & 2.63 & 1.07 & 0.78 \\
\hline
\end{tabular}

Transformational leadership variables demonstrate much higher correlations with workplace spirituality and work engagement than work engagement with workplace spirituality (refer to Table 2). According to the theory of workplace spirituality, employees feel connected to their colleagues and the institutions they work for and a congruence between their values and the values of the institution. They feel a sense of accomplishment in the job. All these factors are an indication that the employees feel as part of the system, they tend to work with a purpose, building esteem in the job and in a way feel a sense of belonging to the institution. This study, thus is trying to identify a correlation exists between work engagement and workplace spirituality, which is narrowing the gap between these two variables. Also, trying to proof the correlational study which has not been attempted elsewhere in the literature reviews.

\section{Table 2}

Pearson's Correlation of Independent Variables and Dependent Variables

\begin{tabular}{llcc}
\hline Independent Variables & Dependent Variables & Pearson $(r)$ & $p$ \\
\hline Transformational Leadership & Workplace Spirituality & $0.691^{* *}$ & 0.00 \\
Transformational Leadership & Work Engagement & $0.522^{* *}$ & 0.00 \\
Work Engagement & Workplace Spirituality & $0.364^{* *}$ & 0.00 \\
\hline
\end{tabular}

**Correlation is significant at $\mathrm{p}<0.01$ 
The results of the correlation analysis in Table 2 show a significant positive correlation between transformational leadership and workplace spirituality and between transformational leadership and work engagement. The study throws light on the fact that if the academic employees find the leadership style at the university is transformational with increase in idealized influence, inspirational motivation, intellectual stimulation and individualized consideration; this positively affects the intention of the employees to stay with their current institutions and achieve greater job satisfaction and enrichment thus reducing the turnover rate of academic employee's departure to other institutions.

Table 3

The Influence of Transformational Leadership on Workplace Spirituality

Independent Variables Dependent Variable - Workplace Spirituality

Transformational Leadership $\left(\mathrm{H}_{\mathrm{A} 1}\right)$

\begin{tabular}{llll}
$-\quad$ Idealized Influence & $.547^{*}$ & $.385^{*}$ & $.517^{*}$ \\
$-\quad$ Inspirational Motivation & $.332^{*}$ & $.388^{*}$ & $.492^{*}$ \\
$-\quad$ Intellectual Stimulation & $.414^{*}$ & $.274^{*}$ & $.379^{*}$ \\
$-\quad$ Individualized Consideration & $.236^{*}$ & $.224^{*}$ & $.138^{*}$ \\
\hline $\mathrm{R}$ & .790 & .549 & .808 \\
$\mathrm{R}^{2}$ & .624 & .314 & .653 \\
Adjusted R & .621 & .310 & .651 \\
F-statistics & 226.88 & 153.12 & 171.31 \\
Durbin-Watson & 1.67 & 1.43 & 1.59 \\
\hline
\end{tabular}

* significant at $\mathrm{p}<0.01 \quad 1=$ Conditions for community, $2=$ Meaning at work, $3=$ Inner life

The first hypothesis $\left(\mathrm{H}_{\mathrm{Al}}\right)$ about the influence of transformational leadership on workplace spirituality is tested using multiple regression analysis. The more detailed picture of the relationship between transformational leadership and workplace spirituality at construct level and factor levels were revealed by the findings of regression analysis. Table 3 summarizes the regression results of the regression analysis at the construct level. The data indicate that transformational leadership style accounts for 62 percent of the variance in conditions for community (adjusted $R^{2} 0.621$ ), 31 percent of the variance in meaning at work (adjusted $R^{2} 0.310$ ) and 65 percent of variance in inner life (adjusted $R^{2} 0.651$ ). The results confirm the alternative hypothesis of transformational leadership as having a positive influence on workplace spirituality and is accepted. Thus, the hypothesis $\mathrm{H}_{\mathrm{A} 1}$ is supported. All the 4 independent variables of transformational leadership idealized influence, inspirational motivation, intellectual stimulation and individualized consideration has positive and significant influence on workplace spirituality.

Table 4

The Influence of Transformational Leadership on Work Engagement

\begin{tabular}{llll}
\hline Independent Variables & \multicolumn{3}{l}{ Dependent Variable - Work Engagement } \\
\hline Transformational Leadership $\left(\mathrm{H}_{\mathrm{A} 2}\right)$ & $B_{1}$ & $\beta_{2}$ & $\beta_{3}$ \\
- Idealized Influence & & & $.117^{*}$ \\
- Inspirational Motivation & $.442^{*}$ & $.185^{*}$ & $.292^{*}$ \\
- Intellectual Stimulation & $.418^{*}$ & $.286^{*}$ & $.349^{*}$ \\
- Individualized Consideration & $.422^{*}$ & $.312^{*}$ & $.238^{*}$ \\
\hline $\mathrm{R}$ & $.336^{*}$ & $.229^{*}$ & .608 \\
$\mathrm{R}^{2}$ & .550 & .632 & .512 \\
Adjusted $\mathrm{R}^{2}$ & .498 & .551 & .489 \\
F-statistics & .491 & .548 & 121.33 \\
Durbin-Watson & 136.23 & 123.72 & 1.52 \\
\hline
\end{tabular}

* significant at $\mathrm{p}<0.01 \quad 1=$ Vigour, $2=$ Dedication, $3=$ Absorption

The second hypothesis $\left(\mathrm{H}_{\mathrm{A} 2}\right)$ about the influence of transformational leadership on work engagement is tested using multiple regression analysis. The more detailed picture of the relationship between transformational leadership and work engagement at construct level and factor levels were revealed by the findings of regression analysis. Table 4 summarizes the regression results of the regression analysis at the construct level. The data indicate that transformational leadership style accounts for 49 percent of the variance in vigour (adjusted $\left.R^{2} 0.491\right)$, 54 percent of the variance in dedication (adjusted $R^{2} 0.548$ ) and 48 percent of variance in absorption (adjusted $R^{2} 0.489$ ). The results confirm the alternative hypothesis of transformational leadership as having a positive influence on work engagement and is accepted. Thus, the hypothesis $\mathrm{H}_{\mathrm{A} 2}$ is supported. All the 4 independent variables of transformational leadership; idealized influence, inspirational motivation, intellectual stimulation and individualized consideration has positive and significant influence on work engagement. 
Table 5

The Influence of Work Engagement on Workplace Spirituality

\begin{tabular}{|c|c|c|c|}
\hline Independent Variables & Dependent V & ble - Workp & pirituality \\
\hline & $\beta_{1}$ & $\beta_{2}$ & $\beta_{3}$ \\
\hline Work Engagement $\left(\mathrm{H}_{\mathrm{A} 3}\right)$ & & & \\
\hline - Vigour & $.113^{*}$ & -.105 & $.221 *$ \\
\hline - Dedication & $.087 *$ & $.465^{*}$ & $.112 *$ \\
\hline - Absorption & $.102 *$ & $.051^{*}$ & $.219^{*}$ \\
\hline$\overline{\mathrm{R}}$ & .209 & .219 & .308 \\
\hline $\mathrm{R}^{2}$ & .114 & .110 & .123 \\
\hline Adjusted $\mathrm{R}^{2}$ & .107 & .103 & .118 \\
\hline F-statistics & 86.88 & 71.32 & 63.64 \\
\hline Durbin-Watson & 1.07 & 1.08 & 1.06 \\
\hline
\end{tabular}

The third hypothesis $\left(\mathrm{H}_{\mathrm{A} 3}\right)$ about the influence of work engagement on workplace spirituality is tested using multiple regression analysis. The more detailed picture of the relationship between work engagement on workplace spirituality at construct level and factor levels were revealed by the findings of regression analysis. Table 5 summarizes the regression results of the regression analysis at the construct level. The data indicate that work engagement accounts for 10 percent of the variance in vigour (adjusted $R^{2} 0.107$ ), 10 percent of the variance in dedication (adjusted $R^{2} 0.103$ ) and 11 percent of variance in absorption (adjusted $R^{2} 0.118$ ). The results confirm the alternative hypothesis of work engagement as having a positive influence on workplace spirituality albeit at a much lower strength level and is accepted. Thus, the hypothesis $\mathrm{H}_{\mathrm{A} 3}$ is supported. All the 3 independent variables of work engagement; vigour, dedication and absorption have positive and significant influence on workplace spirituality.

\section{Discussion}

The study aimed to make a contribution towards the understanding of work engagement of academic employees in the PHEIs in Malaysia towards workplace spirituality and also to gain more understanding on the variables involved. A further aim of this study is to establish whether the transformational leadership style model that has been used to predict work engagement can also predict workplace spirituality of academic employees. The results of the study have made an important theoretical contribution in the respect as no results were reported in previous studies in the Asian context regarding the work engagement and workplace spirituality of employees.

Our findings suggest that transformational leadership behaviours positively influenced the academic employees' mental and spiritual well-being through their abilities to create a strong sense of community in the workplace. As predicted, the direct relationship between transformational leadership and workplace spirituality of academic employees in $\mathrm{H}_{\mathrm{A} 1}$ was supported. Certainly, there is an extensive body of literature documenting the beneficial effects of support from managers (Petchsawang $\&$ Duchon, 2009). These data show that managerial support has been linked with lower levels of perceived stress, job strain, burnout and depression (Rego \& Cunha, 2008; Roof, 2015; Gatling \& Milliman, 2016). Second, this study identified that transformational leadership creates meaning in work that followers do.

As predicted, the direct relationship between transformational leadership and work engagement in $\mathrm{H}_{\mathrm{A} 2}$ was supported. First, the findings demonstrate that employees who have transforming managers are more likely to be energetic, dedicated and absorbed in work. The results of this hypothesis among academic employees is in line with previous studies conducted in South Africa (Van der Walt \& Swanepoel, 2015), the Netherlands (Tims et al., 2011) and Portugal (Salanova et al., 2011). The present study has important implications in the field of employee work engagement and leadership because it is one of the few studies examining the predictive relationship between manager/leader attitude/behaviour and the relationship it can have on driving employee energy, dedication, and engagement levels at work. Since there is little previous literature directly measuring the relationship of these two variables, this study adds to the growing body of knowledge on the subject.

Another important objective of the study was to determine the relationship between work engagement and workplace spirituality. The findings also indicate that work engagement was positively and significantly related to workplace spirituality. The relationship between work engagement and workplace spirituality was moderately positive, and the $\mathrm{H}_{\mathrm{A} 3}$ hypothesis is thus accepted. This suggests that higher levels of work engagement could lead to higher levels of workplace spirituality. As such, organisations could potentially promote work engagement (vigour, dedication \& absorption), by focusing more on workplace spirituality. Although the relationships between work engagement and workplace spirituality were significant, the variance was low. Therefore, although a statistically significant relationship emerged, it may be practically insignificant.

The finding of a positive association between work engagement and workplace spirituality is consistent with Roof (2015) and Saks (2011). When employees are allowed to express themselves at the spiritual level in their workplace, they will, according 
to Saks (2011), be more engaged in their work. Additionally, the strongest correlation among the dimensions of work engagement and workplace spirituality were between meaningful work and dedication $(\beta=0.465, p=.000)$. The potential explanation of this result is that, when people find their work to be meaningful, they feel inspired by, enthusiastic about, and dedicated to their work. Shrestha (2016) claimed that spiritual employees find their work meaningful, and meaningful work strengthens their work engagement.

\section{Conclusion}

The current study elaborated on the research findings of previous studies, confirming the importance of creating spiritually based workplaces in order to ensure that employees are satisfied with, and involved in, their jobs. However, organizations should realise that workplace spirituality cannot be used as a "quick fix" to solve organizational problems, but should be implemented authentically, and lived by organizational leaders, if it is to have positive outcomes for the organization.

\section{Limitation of the Study}

Like all research, this study has both strengths and weaknesses. In terms of limitations, the study is a cross-sectional study and so, as referenced above, no inferences can be made about causality. Longitudinal research is required to see if the effects hold up over time. The study is also based on self-report data from limited source (only 4 private higher education institutions participated in this study) and, as such, is prone to all of the limitations and biases inherent in such an approach. However, this data collection method is the one most often used in leadership studies (Bass et al., 1999). It has been argued that, because of their vantage point, employees are in the best position to evaluate leaders' range of behaviours, so it is appropriate they provide study data (Meyer \& Gagne, 2008). Empirically, the large number of small, non-significant correlations observed in our data substantially limits the possibility that our findings are inflated through common method variance (Hair et al., 2010). The fact that the study explores deeply personal areas, namely work engagement and workplace spirituality, also makes the use of surveys somewhat problematic. As pointed out by Kim and Park (2017) and Kahn (2010), respectively, the nature of workplace spirituality and work engagement may not lend themselves to effective study through a survey instrument. We attempted to partly address such concerns by using well-known and validated scales, such as the spiritual well-being scale. We operationalized workplace spirituality in a particular way, and some may take issue with our conceptualization.

\section{Funding}

This work was funded by Xiamen University Malaysia Research Fund (Grant No. XMUMRF/2018-C2/ISEM/0002).

\section{Acknowledgement}

The authors would like to thank the anonymous referees for constructive comments on earlier version of this paper.

\section{References}

Abdullah, H. S., \& Kaliannan, M. (2006). Development of e-government in Malaysia: The role of leadership and organisational efficacy. In R. K. Mitra (Ed.), egovernment: Macro Issue (pp. 189-202). New Delhi India: GIFT Publishing.

Ansari, M. A., Ahmad, Z. A., \& Aafaqi, R. (2004). Organizational leadership in the Malaysian context. In Tjosvold, D., \& Leung, K. (2004). Leading in high growth Asia: Managing relationship for teamwork and change. World Scientific.

Ashmos, D. P., \& Duchon, D. (2000). Spirituality at work: A conceptualization and measure. Journal of management inquiry, 9(2), 134-145.

Bakker, A. B., Schaufeli, W. B., Leiter, M. P., \& Taris, T. W. (2008). Work engagement: An emerging concept in occupational health psychology. Work \& stress, 22(3), 187-200.

Bass, B. M., \& Avolio, B. J. (1993). Transformational leadership: A response to critiques.

Avolio, B. J., Bass, B. M., \& Jung, D. I. (1999). Re-examining the components of transformational and transactional leadership using the Multifactor Leadership. Journal of occupational and organizational psychology, 72(4), 441-462.

Chawla, V. (2014). The effect of workplace spirituality on salespeople's organisational deviant behaviours: research propositions and practical implications. Journal of Business \& Industrial Marketing, 29(3), 199-208.

Chong, C. W., Yuen, Y. Y., \& Gan, G. C. (2014). Knowledge sharing of academic staff: A comparison between private and public universities in Malaysia. Library Review, 63(3), 203-223.

Daniel, J. L. (2015). Workplace spirituality and stress: Evidence from Mexico and US. Management Research Review, 38(1), 29-43.

Dhiman, S., \& Marques, J. (2011). The role and need of offering workshops and courses on workplace spirituality. Journal of Management Development, 30(9), 816-835.

Fachrunnisa, O., \& Adhiatma, A. (2014). THE ROLE OF WORK PLACE SPIRITUALITY AND EMPLOYEE ENGAGEMENT TO ENHANCE JOB SATISFACTION AND PERFORMANCE. International Journal of Organizational Innovation, $7(1)$. 
Gatling, A., Kim, J., \& Milliman, J. (2016). The relationship between workplace spirituality and hospitality supervisors' work attitudes: A self-determination theory perspective. International Journal of Contemporary Hospitality Management, 28(3), 471-489.

Geh, E., \& Tan, G. (2009). Spirituality at work in a changing world: managerial and research implications. Journal of Management, Spirituality and Religion, 6(4), 287-300.

Gupta, M., Kumar, V., \& Singh, M. (2014). Creating satisfied employees through workplace spirituality: A study of the private insurance sector in Punjab (India). Journal of business ethics, 122(1), 79-88.

Hair, J. F., Black, W. C., Babin, B. J., Anderson, R. E., \& Tatham, R. L. (2006). Multivariate data analysis (Vol. 6).

Kahn, W. A. (2010). The essence of engagement: Lessons from the field. Handbook of employee engagement: Perspectives, issues, research and practice, 20-30.

Kim, W., \& Park, J. (2017). Examining structural relationships between work engagement, organizational procedural justice, knowledge sharing, and innovative work behavior for sustainable organizations. Sustainability, 9(2), 205.

Meyer, J. P., \& Gagne, M. (2008). Employee engagement from a self-determination theory perspective. Industrial and Organizational Psychology, 1(1), 60-62.

Milliman, J., Czaplewski, A. J., \& Ferguson, J. (2003). Workplace spirituality and employee work attitudes: An exploratory empirical assessment. Journal of organizational change management, 16(4), 426-447.

Nam Nguyen, H., \& Mohamed, S. (2011). Leadership behaviors, organizational culture and knowledge management practices: An empirical investigation. Journal of Management Development, 30(2), 206-221.

Nielsen, K., Randall, R., Yarker, J., \& Brenner, S. O. (2008). The effects of transformational leadership on followers' perceived work characteristics and psychological well-being: A longitudinal study. Work \& Stress, 22(1), 16-32.

Petchsawang, P., \& Duchon, D. (2009). Measuring workplace spirituality in an Asian context. Human resource development international, 12(4), 459-468.

Rahman, M. S., Mat Daud, N., Hassan, H., \& Osmangani, A. M. (2016). Effects of workplace spirituality and trust mediated by perceived risk towards knowledge sharing behaviour. VINE Journal of Information and Knowledge Management Systems, 46(4), 450-468.

Rahman, M. S., Osmangani, A. M., Daud, N. M., Chowdhury, A. H., \& Hassan, H. (2015). Trust and work place spirituality on knowledge sharing behaviour: Perspective from non-academic staff of higher learning institutions. The Learning Organization, 22(6), 317-332.

Rani, N. S. A., Pa'wan, F., Musa, N. C., \& Tajudin, M. M. (2008). Malaysian Employees' Preference of Their Managers Leadership Style. International Review of Business Research Papers, 4(5), 97-108.

Rego, A., \& Pina e Cunha, M. (2008). Workplace spirituality and organizational commitment: an empirical study. Journal of organizational change management, 21(1), 53-75.

Roof, R. A. (2015). The association of individual spirituality on employee engagement: The spirit at work. Journal of Business Ethics, 130(3), 585-599.

Saks, A. M. (2011). Workplace spirituality and employee engagement. Journal of management, spirituality \& religion, 8(4), 317-340.

Salanova, M., Agut, S., \& Peiró, J. M. (2005). Linking organizational resources and work engagement to employee performance and customer loyalty: the mediation of service climate. Journal of applied Psychology, 90(6), 1217.

Singh Sandhu, M., Kishore Jain, K., \& Umi Kalthom bte Ahmad, I. (2011). Knowledge sharing among public sector employees: evidence from Malaysia. International Journal of Public Sector Management, 24(3), 206-226.

Schaufeli, W. B., \& Bakker, A. B. (2004). Job demands, job resources, and their relationship with burnout and engagement: A multi-sample study. Journal of Organizational Behavior: The International Journal of Industrial, Occupational and Organizational Psychology and Behavior, 25(3), 293-315.

Schaufeli, W. B., Taris, T. W., \& Van Rhenen, W. (2008). Workaholism, burnout, and work engagement: three of a kind or three different kinds of employee well-being? Applied psychology, 57(2), 173-203.

Selvarajah, C., \& Meyer, D. (2008). One nation, three cultures: exploring dimensions that relate to leadership in Malaysia. Leadership \& Organization Development Journal, 29(8), 693-712.

Shrestha, A. K. (2016). Further Validation of Workplace Spirituality Scale in an Eastern Context. Journal of Business and Management Research, 1(1), 1-13.

Sadiq Sohail, M., \& Daud, S. (2009). Knowledge sharing in higher education institutions: Perspectives from Malaysia. Vine, 39(2), 125-142.

Tims, M., Bakker, A. B., \& Xanthopoulou, D. (2011). Do transformational leaders enhance their followers' daily work engagement? The Leadership Quarterly, 22(1), 121-131.

Van der Walt, F., \& Swanepoel, H. (2015). The relationship between workplace spirituality and job involvement: A South African study. African Journal of Business and Economic Research, 10(1), 95-116.

Wahid, N. K. A., \& Mustamil, N. M. (2014). Communities of Practice, Workplace Spirituality, and Knowledge Sharing. International Business and Management, 9(1), 35-43. 


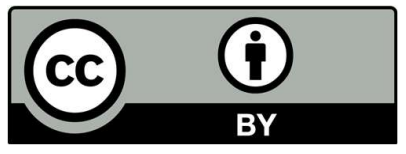

(C) 2020 by the authors; licensee Growing Science, Canada. This is an open access article distributed under the terms and conditions of the Creative Commons Attribution (CC-BY) license (http://creativecommons.org/licenses/by/4.0/). 